\title{
Guest editorial: governing the challenges of climate change and energy transition in cities
}

Thomas Hoppe ${ }^{1 *}$ and Ellen van Bueren ${ }^{2}$

\begin{abstract}
Cities form the key context within which social, economic and environmental challenges for sustainable development will manifest in the years to come. As they face the grand societal challenges of climate change and the greening of energy systems, city governments are confronted with the challenge of designing and implementing workable policy strategies. We find that although much attention has been paid to low carbon energy transition in cities, there is surprisingly little attention to the dimension of governance, policy and politics in the scholarly literature. The main question in this guest editorial of the thematic issue, entitled 'Governing the Climate Change Mitigation and Energy Transition Challenges in Cities', is: How can effective policy strategies be designed and implemented to govern the challenges of climate change and energy transition in cities? We develop some preliminary answers to this question based on seven research papers that form the contribution to the thematic series. In particular, the various roles that cities play in governing the climate change challenges and energy transition require further description and analysis, specifying the different governing roles of urban actors and how the city-socially, institutionally or geophysically_forms the context within which governance initiatives and arrangements are formed and implemented, while cities themselves are in turn part of larger physical, infrastructural and institutional networks that influence and condition the local governance opportunities. A research agenda to explore the topic further must include particularly the following areas: the role of local government in the interplay between governance initiatives at multiple levels, the influence and the confluence of current (sectoral) policies, learning from a variation of practices of local low carbon policy, mapping the institutional dimension, mapping design and implementation practices of urban low carbon policy, assessing the effects and legitimacy of urban low carbon policies, further understanding of strategic action fields and lines of conflicts between (coalitions of) actors and identifying workable governance frameworks and policies supporting community-led energy initiatives.
\end{abstract}

Keywords: Energy transition; Climate change mitigation; Low carbon strategy; Cities; Governance

\section{Introduction}

Cities form the key context within which social, economic and environmental challenges for sustainable development will manifest in the years to come. As they face the grand societal challenges of climate change and the greening of energy systems, city governments are confronted with the challenge of designing and implementing workable policy strategies. Given the degree of urban and institutional complexity involved, this is more than just another governance challenge. Searching for solutions in outdated governance and network modes

\footnotetext{
*Correspondence: t.hoppe@utwente.nl

'Department of Governance and Technology for Sustainability (CSTM), Faculty of Behaviour, Management and Social Sciences (BMS), University of Twente, P.O. Box 217, Enschede 7500 AE, The Netherlands

Full list of author information is available at the end of the article
}

and deploying old-fashioned top-down policy instruments will likely invite failure and bitter disappointments. Contemporary cities might be on the lookout for innovative governance modes that are more likely to succeed in coping with technological innovations, active civil society movements and new modes of entrepreneurship. Such issues show that there is a need to explore best practices and innovative but proven principles of new governance modes and policy arrangements that cities can deploy against the challenges of climate change mitigation and energy transition. This is the topical focus of this thematic series in Energy, Sustainability and Society. It explores new avenues regarding the role(s) that cities can play and the governance strategies that they can use in urban low carbon energy transitions 
and addresses conceptual, design-oriented and empirical bodies of literature. The main research question of the thematic series is therefore: 'How can effective policy strategies be designed and implemented to govern the challenges of climate change and energy transition in cities?'

This thematic series results from a panel session organised at the 2013 EURA conference (European Urban Research Association) at the University of Twente, Enschede, The Netherlands. The panel session allowed multiple issues to be presented that are relevant to energy transition and low carbon policy strategies in cities: e.g. assessment of climate change mitigation policies and practices, management of energy transition in cities, citizen participation, stakeholder involvement in policymaking processes, the role of grass-roots movements, urban living labs, smart grids, high energy-efficient buildings and development of new modes of collaboration and governance to foster the achievement of low carbon and energy goals. The objective of the panel session was to contribute to an evaluative framework for urban sustainable transition policies which builds on the rich theories of the policy process. As such, it contributes to the research agenda of the colloquium on 'Energy and Climate Governance' of the Netherlands Institute of Government (NIG), which is co-chaired by the guest editors of this thematic series. Hence, the thematic series should also be seen as a contribution to a research agenda that focuses on governance and policy issues related to low carbon energy transition. In a previous special issue by the guest editors [1], a research agenda was offered which suggested focusing research on governance of low carbon energy transition on the following items: (i) the role of existing policy regimes vis-à-vis low carbon policy, (ii) the role of institutional and organisational interests, (iii) leadership in the public sphere and (iv) social (and political) acceptance of low carbon energy innovations. Also mentioned was the ambition to bridge the conceptual gap between policy and governance studies on the one hand and transition studies on the other (when addressing low carbon issues in society).

This thematic series offers seven contributions (research papers) from different disciplinary backgrounds: legal sciences, policy studies, public administration, (political) sociology, institutional economy and transition studies. Due to its disciplinary scope, this thematic series differs from the more general stream of energy policy literatures, which predominantly embraces articles from authors with backgrounds in engineering and economy. Of special interest to this thematic series are contributions from legal sciences and sociology (the latter notably on grassroots movements), since they are not often found in the literature on low carbon transitions. They cover theoretical issues that have to do with agency, structure and the role of institutions in local and regional energy systems. We consider it of special importance to address these issues in relation to the complexity of cities. Moreover, the contributions to our thematic series cover a wide range of research objectives, varying from empirical to conceptual and designoriented articles.

This guest editorial is structured as follows. The 'Literature review: cities and low carbon transitions' section refers to the existing literature in the field of governing low carbon energy transitions in cities, in particular to a volume entitled 'Cities and Low Carbon Transitions' edited by Bulkeley et al. [2]. In the next section we address the contributions to this thematic series. In the 'Discussion: positioning the contributions of this special issue in the research agenda on low carbon transition in cities' section, we address what these contributions, and hence this thematic series add to ongoing academic debates. The 'Conclusion and recommendations for a future research agenda' section concludes this paper and introduces a research agenda for 'governing the challenges of climate change mitigation and energy transition in cities'.

\section{Literature review: cities and low carbon transitions}

Although much has been written on cities and low carbon transitions, our focus here is on an edited volume that was published in 2013, which brings together different insights and perspectives addressing the role of cities in low carbon (energy) transitions [2]. The volume combines insights from urban studies and (technological) transition studies to examine, how, why and with what implications cities spur low carbon transitions. It draws on a wide range of examples, including world (mega) cities, ordinary cities and transition towns, covering most of the world's continents, to provide evidence that expectations, aspirations and plans to undertake purposive socio-technical transitions are emerging in different urban contexts. The volume basically contains three chapters which directly address governance and government issues (on 'governing urban low transitions' [3] and on 'municipal bureaucracies' $[4,5])$. Other chapters only cover piecemeal information on the governance of low carbon transitions in cities. We first review the main theoretical propositions addressed in the volume, after which we identify the concepts that we consider relevant to our research question, and which might serve as a stepping stone for developing and elaborating a research agenda to address the 'governance of low carbon energy transitions in cities'.

Geels [6], in his chapter in the 'Cities and Low Carbon Transitions' volume [2], states that cities play three principal roles in technological transition change of 
socio-technical regimes in cities. First, cities (or rather city governments) can be viewed as primary actors enacting transition processes. Second, cities can be viewed as seedbeds and locations for testing, experimenting with and developing radical innovations in the early phases of transition. Third, although there clearly is a role for cities (here, city governments are meant) in transitions, it should not be overestimated for it is limited compared to the influence of market dynamics and other actors. Hence, cities, in their quest to spur transformative change, depend to a large extent on powerful incumbent actors, who have reasons to protect their vested interests, and might therefore be inclined to resist efforts by cities that can potentially endanger their position and interests. Moreover, addressing the role of low carbon transition in cities raises many conceptual and methodological issues. How is the city viewed in the low carbon transition: as an actor able to influence developments, as a niche in which innovations contributing to transitions can be tried and tested or as a regime that forms the constraining context for transformations? And how does it have a relationship to other actors, either 'within' or also 'outside' the city itself [3]?

An important issue addressed in the volume is whether urban low carbon transitions need top-down government policy approaches or rather alternatives that allow for situative governance by empowering community-led initiatives. The rapid evolution of 'Transition Towns' and their diffusion across Europe is a striking example of the latter aspect [7]. The Transitions Town movement, which focuses on supporting community-led responses to 'peak oil, climate change, building resilience and happiness' [8], was founded in 2006 (in Totnes, Devonshire, UK), and by 2013 had diffused to 277 Transition Initiatives in other cities [7], in more than 20 countries. Adherents of the initiative acknowledge that government-led, top-down approaches might have little impact on local communities that have little faith in state institutions with a weak sense of personal agency and little trust in information provided by the state [9].

In this sense, initiatives such as 'Transition Towns' give leeway to the creation of 'alternative spaces' within cities through which often marginalised voices can seek to participate. Crucial in this sense are intermediary organisations and experimental processes, such as using living labs, and the politics through which knowledge and actions are produced within these experiments. The big question is whether management of these alternative spaces for experimentation and learning with low carbon technologies is sufficient to catalyse urban transitions and reshape city regimes-with the expectation that some form of scaling is necessary after niche experimentation has proved successful [3]. Creating Transition
Towns in one or more city districts, however, does not mean that an entire city will successfully undergo a low carbon transitional change. In line with Geels' perspectives on the roles cities can play in transitions [6], much will depend on factors that go beyond a city's span of control. Aligning and coordinating action from key stakeholders in the city-at-large (the city as a system), covering all sectoral domains, geographical city entities and coping with market dynamics remains a tough, complex challenge for city governments (perhaps this can even be judged a 'wicked problem'). Notwithstanding the complexity and 'wickedness' of the challenge ahead, low carbon transitions are inevitable for urgent reasons, in particular for preventing and mitigating the impacts of climate change, while for community reasons, urban low carbon transitions are (more than) worth pursuing [3].

Späth and Rohracher [5] address the interplay between social dynamics and governance strategies implemented by city governments in the historical cases of two 'ecocities', Freiburg (Germany) and Graz (Austria). Although their analysis is balanced and provides many useful insights (e.g. into the role of public managers, political leadership, policy entrepreneurs and different organisational contexts and cultures), it also reveals the limited role city governments can actually play in local transitions and the importance of: (a) supportive framework conditions and (b) cooperation between city governments and higher levels of government. Notwithstanding the importance of the results of the Freiburg and Graz cases, we judge them as unique since the two cities can be viewed as frontrunners (in terms of sustainable city indicators). In this sense, the two cities are hardly representative within the broader set of cities in their respective countries.

The volume [2] also reveals a great deal of scepticism about the intention and organisation of governance strategies. Bulkeley et al. [3] claim that the low carbon urban initiatives are often dominated by a small coalition of actors, often led by narrow interests, and are politically contested. Furthermore, there seems to be a disjuncture in participative terms; policy-led and 'alternative' initiatives are often guilty of the same privileging [3]. The authors also state that low carbon transitions tend to be framed by politicians and public officials in strategic ways to create the impression that policies are implemented in the wider, common interest, whereas the real reason might be disguised (e.g. lowering costs of energy consumption or creating more jobs). In sum, locating cities in low carbon transitions typically leads to analyses that include politics and struggle. One may wonder whether urban low carbon transitions are more manageable than national transitions and whether or to what extent they can be shaped. 
Theoretically, the editors of the 'Cities and Low Carbon Transitions' volume [2], which starts off by introducing transition concepts, particularly the 'multilevel perspective' (MLP) [10], judge that theoretical concepts that try to explain low carbon urban transition need also to reflect on the political dimension of transition. Although the volume offers a handful of insights on governing and the governance of low carbon transition in cities, we feel that a lot of potentially useful issues and theoretical notions deserve to be addressed more extensively, an ambition to which this special issue contributes. Key issues that are of importance to low carbon transition in cities and need more attention include, for instance: improving energy efficiency in postwar social housing (e.g. [11]), the use of smart energy innovations-in particular smart grids (e.g. [12]) or the evaluation of energy conservation programmes in residential areas in cities [13].

With its focus on the disciplines of urban studies and transition studies, the volume 'Cities and Low Carbon Transitions' [2] seems, somewhat understandably, to have neglected theories about politics, governance and policy. Although the volume [2] offers many valuable insights into 'low carbon transitions in cities', it is limited in disclosing information on the institutional, political, governance and policy dimensions. We feel that there is a need to show that these dimensions have more to offer than simply stating that urban low carbon energy transition are 'subject to politics and struggle'.

\section{Contributions to this thematic series}

Community initiatives for renewable energy are emerging throughout Europe, albeit in varying numbers, with variable success rates and different strategies. In their contribution to this thematic series, Arentsen and Bellekom [14] focus on local energy initiatives as 'seedbeds of innovation' in a Schumpeterian sense. The authors address the issue of how such initiatives can lead to innovations in the energy supply. The paper analyses the causes and manifestations of local community initiatives in the Netherlands, to discover the drivers and foci of these initiatives. Theoretically, the paper provides an institutionally oriented classification of local electricity initiatives, based on coordination, technology and performance. The results reported in the paper show that although local (decentralised) electricity initiatives can be considered seedbeds of innovation, it is unlikely that they have the potential to progress to dominance of the electricity supply system. Local energy initiatives are more likely to develop as niches inside the dominant central electricity generation system, contributing to hybridisation of its products and services.

In a similar vein, Oteman et al. [15] address local renewable energy initiatives from an institutional and policy arrangements perspective. They describe historical developments in three European countries: Germany, Denmark, and The Netherlands, placing it within the institutional context of the policies, power structures and energy discourses of each country. The article identifies structural, strategic and biophysical conditions for community success. The results show that institutional arrangements of the energy policy subsystem can both constrain and enable community energy projects. Alignment of discourses across government levels and actors is one of the important enabling features of an energy system, as it provides the stability and predictability of the system that enables communities to engage in renewable energy projects. The (evolving) institutional configuration of the energy sector strongly influences the space available for community initiative development and differs between countries.

The contribution to this thematic series by Fuchs and Hinderer [16] addresses decentralised energy initiatives from a governance and policy perspective. Sustainabilityoriented energy transitions are reliant on various sorts of renewable energies coupled with decentralised energy efficiency initiatives. Important technical and institutional innovations for energy transitions are being developed, tested and brought to application at the regional and local level in the realm of existing regulatory and market frameworks. Regions, cities and villages experimenting with socio-technical innovations and aiming to implement new concepts have to develop governance structures under conditions of great uncertainty. These governance structures mirror space-specific social, political, technological and economic constellations. The authors then introduce an analytical approach from political sociology-'Theory of strategic action fields; Lines of conflict'-for studying emergent forms of governance. They apply the framework to four case studies in Germany. The key results of the study hold that sustainable energy transitions do not follow a master plan nor are they coordinated at national level. Rather, a variety of actors are involved with different aims and interests, culminating in the development of spacespecific technological mixes and situative governance structures. Such local configurations harbour lines of conflict between (coalitions) of actors pursuing different interests.

Sanders et al. [17] address the role of policy incentives in support of local energy initiatives. They focus on the legitimacy of reward systems, arguing that legitimacy of political authority is a major criterion of government policy- and decision-making and implementation in the challenge of spurring low carbon energy transition in cities and regions. Major building blocks of this legitimacy are the principles of liberal democracy and of the rule of law. The aim of the article is to identify safeguards for a 
legitimate exercise of political authority in interactive regional governance initiatives. Experience with the implementation of reward systems is assessed in-depth, introducing a case study in The Netherlands. The dimension of legitimacy and the normative concept and role of the regulatory state have hardly been addressed in the scholarly literature devoted to low carbon transition, let alone transition studies (except as 'regime' constraints on sustainable transitions). The key lesson from [17] is that legitimacy is never a given standard; it may be designed into structures and ambitions, but it will still need to be achieved by proper practice. This is certainly the case in projects involving sustainability challenges, effective solutions for which are by no means clear and readily deployable. As reward systems and competitions offer potential leeway for local energy initiatives, they can only function if they are legitimately founded and implemented in 'proper practice'.

A contribution to this thematic series on the policy dimension is the article by Hoppe et al. [18], who address implementation and the challenges of local climate change policy in cities. The article presents the results of a study of the implementation of two climate change policy lines: adaptation and mitigation. In particular, the issue of the assumed 'dichotomy' between adaptation and mitigation is addressed. The results show that although climate change has been a major environmental policy issue and has been on the policy agenda of cities for years, adaptation is still considered an 'add-on' to climate change mitigation policy. Moreover, the adoption and implementation of both adaptation and mitigation measures suffer from institutional inertia in local policy practice. Differences in approach, however, are in large part due to institutional inertia and the framing of policy debates: mitigation is viewed as an 'energy' issue whereas adaptation is viewed as a 'water' issue (two discourses). This view is well institutionalised in current policy frameworks. In practice, cities have to cope with both adaptation and mitigation, and are challenged to seek cross-linkages, to design 'no regret options' (such as 'green roofs') and other solutions with 'co-benefits'. The case of local climate change mitigation policy also addresses how central government can capture and dominate local policy agendas using intergovernmental support schemes.

Whereas urban energy transition studies devoted a lot of attention to addressing the large-scale adoption of sustainable energy technology, one should not forget the potential for lowering energy consumption by improving energy efficiency standards in residential and industrial areas. Viétor et al. [19] address this issue by focusing on the uptake and integration of decentralised combined heat and power (CHP) units in urban energy systems in the German Ruhr area. Although decentralised CHP units have a high potential in this region, local action plans by city governments show only modest developments in this technology. The central research question in this article addresses factors affecting uptake and integration of decentralised CHP. The study showed that observed barriers relate to: (i) lack of market services such as financial means for making investments, (ii) lack of user awareness such as unawareness and an information deficit regarding the benefits of decentralised CHP to potential users, (iii) the presence of centralised district heating systems, (iv) policy issues such as lack of adequate policies in support of the diffusion of decentralised CHP units, poor alignment with social housing policy and ownership of district heating systems (via concessions contracts), (v) sector issues, such as a lack of skilled service providing companies and (vi) industrial, vested interests of the coal and gas industry. Moreover, many of these barriers seem to be inter-related, especially those concerning policy and finance available for making upfront investments.

In the final contribution to the thematic issue, Stauskis [20] presents the issue of co-creation and citizen participation in sustainable city design and planning processes. The aim of the article is to verify how specific methods of virtual reality simulation could be used as an effective tool for setting an efficient participation platform between the stakeholders to improve environmental, social and energy sustainability of urban development in modern cities. The author introduces a methodology to do this and presents the case of Vilnius City in which the methodology has been applied in a project. The study shows that virtual reality and spatial modelling integrated in gaming platforms using widely available information and communications technology (ICT) applications has the potential to spur public involvement in urban planning processes, which increases the public's attention to urban planning on the social, environmental and low carbon dimensions.

\section{Discussion: positioning the contributions of this special issue in the research agenda on low carbon transition in cities}

Concerning the possible roles of cities in technical transitions, and using the results from the contributions to the thematic series, we reflect on the propositions offered by Geels [6] that cities can act as primary actors enacting transitions and as seedbeds for radical innovations in the early phases of transition-including his warning not to overestimate the power of cities-in the overall energy system, since their role is often modest. Given the contributions to this thematic series, a few observations deserve to be mentioned here. First, although we partly agree with the claim that cities are the primary 
actors-assuming that by cities local governments are meant-enacting transition (e.g. [19]), many of the contributions to this thematic issue point out that it is community-led organisations that initiate low carbon energy transitions, not city governments. Second, urban initiatives are strongly driven by national and regional governments implementing intergovernmental policies (particularly in the form of support schemes) to support local governments in the design and implementation of low carbon policies and empowering local communities to take low carbon action of their own (see contributions $[17,18])$. Hence, the direct influence of city governments on local low carbon policy seems rather limited due to interference from other (higher level) levels of governments (c.f. [5]). Third, the contributions by Fuchs and Hinderer [16] and Oteman et al. [15] address the ways in which community-led initiatives depend on institutional configurations and policy arrangements. Finally, in line with Geels' claim that powerful incumbents can slow down transition processes in cities [6], the contribution by Viétor et al. [19] shows that large-sized energy companies with the authority to manage and operate energy infrastructures impede the diffusion of promising low carbon energy technology in urban areas.

When reflecting on other theoretical claims raised in 'Cities and Low Carbon Transitions' volume [2], this thematic series also offers an interesting elaboration. A key issue raised by Bulkeley et al. [3] was how to perceive the (role of) cities in low carbon transitions: as an actor, a niche or a regime and whether cities only have relationship to other actors 'within' or also 'outside' cities? Given the insights provided by the contributions to this thematic series, cities can be seen as both actors, niches and regimes. As an actor, a city can be viewed as local government pursuing the common interest and making move to encourage low carbon energy transitions. City governments can do this when adapting different roles and using a comprehensive set of policy instruments to spur action among local stakeholders having any relevance to the production, distribution or consumption of energy. This also applies to finding room for niche experimentation by providing financial support, offering regulatory exemption or determining that a given spatial zone is allowed to be used for niche experimentation; e.g. installation of decentralised CHP units in municipalities [19], or use of living labs allowing citizens to join in virtual urban simulations (VUS) and participate and cocreate in city design and planning processes [20]. The argument that cities can be seen as niches is supported by both this argumentation and niche experiments that start bottom-up from community-led initiatives, notably renewable energy initiatives as a 'seedbed for innovation' (cf. [14, 15]). However, practice shows that these initiatives are in dire need of government support. In some cases, government support was even the main reason that local energy initiatives started up in the first place [17]. An important reason for needing government support is the presumption that many local energy initiatives have to face incumbent energy regimes exerting forces with which they cannot cope single-handedly. In the contributions by Fuchs and Hinderer [16], Oteman et al. [15] and Arentsen and Bellekom [14], it is argued that citizen-led renewable energy initiatives have to face and comply with institutional regimes that are managed under the authority of incumbent actors. In this sense, it is fair to state that cities can also be seen as socio-technical (and in particular institutional) systems that are very comprehensive, locked in and hard to challenge. For this reason, Arentsen and Bellekom [14] predict that communityled renewable energy initiatives are not expected to challenge the existing electricity supply system.

Regarding the dependence of cities on regional and central government, important reflections can be presented based on the empirical contributions by Fuchs and Hinderer [16], Oteman et al. [15] and Hoppe et al. [18]. The latter show that the majority of cities in The Netherlands, implementing low carbon energy policy actively used the national government's intergovernmental support schemes, utilising blueprints describing how local low carbon policy was best to be designed and executed. This practice illuminates the dependency cities have on resources offered by 'higher' governments. One might wonder how and to what extent these multilevel policy instruments influence agenda setting of low carbon policies in cities.

This touches on another important issue raised by Bulkeley et al. [3]. Does urban low carbon transition require top-down governing or rather situative governance, empowering bottom-up civil society initiatives? Evidence from the contribution to this topical issue by Fuchs and Hinderer [16] supports the latter. Results from other contributions $[15,17,18]$, however, sketch a more nuanced view of this issue: bottom-up approaches are essential for urban low carbon transitions but cannot survive without (some form of) government support. Moreover, Sanders et al. [17] claim that support policies will only be any use if they are legitimate. The excessive involvement of (central or regional) government, however, bears the risk that general 'blueprints' are designed and, in combination with financial-economic incentives, are implemented in ways that allow for scaling, but with limited attention to situational conditions and local community preferences. As Hoppe et al. [18] show, blueprint approaches may encourage local capacities, but do not guarantee sound and effective policy implementation. As citizens are becoming better informed, interconnected 
(using social media) and more capable of expressing their needs and wants, they will request more transparency and participation in managing energy utilities. In light of this development, local governments might want to seek new modes of governance that allow the empowerment of the citizenry to a greater degree than one was once accustomed to.

In this sense, it is also important to address the issue of framing low carbon urban energy transitions in agenda-setting and policy-making. Fuchs and Hinderer [16] show that these frames often relate to narratives held by advocacy coalitions and that they are used in strategic action fields. Hoppe et al. [18] show that framing is highly influential in local climate change policy debates and policy implementation. Although climate change action in cities could essentially address both the issues of adaptation and mitigation, it is low carbon (mitigation) strategies that are especially practiced. As a consequence, promising 'no-regret' options (solving both adaptation and mitigation problems) are largely neglected. A key reason for this 'adaptation-mitigation dichotomy' is institutional inertia, which erroneously qualifies mitigation as an 'energy' (only) issue and adaptation as a 'water' (only) issue.

Finally, we want to address the proposition by Bulkeley et al. [3] regarding theoretical concepts (in particular MLP) trying to explain low carbon urban transition, that need to reflect (more) on the political dimension of transition (a criticism that is in line with other scholars criticising MLP for neglecting issues like politics, power and more particularly agency). In the empirical-conceptual contributions by Arentsen and Bellekom [14], Viétor et al. [19] and Fuchs and Hinderer [16], this proposition is supported by evidence, and all three contributions offer conceptual or methodological approaches to address this issue.

\section{Conclusion and recommendations for a future research agenda}

This guest editorial started with the research question 'How can effective policy strategies be designed and implemented to govern the challenges of climate change and energy transition in cities?' The seven contributions to this thematic series provide a lot of answers and are also useful in elaborating the current debate on low carbon transitions in cities.

The contributions reveal the variety of roles played by 'cities' in the energy transition, including more proactive, initiating ones-sometimes reviving the former, pre-liberalisation role of the incumbent-and more facilitating roles, supporting energy initiatives for which the city serves as a locus and in which local government fulfils a similar role to what it used to do with community initiatives. Especially in the field of community initiatives, the city is considered to be more the scene or stage for community initiatives rather than the driving force behind them. The motives for starting and joining these initiatives are highly varied and so are the evolving organisational arrangements of these initiatives. The situative or contingent nature of these initiatives is reflected in their institutional setup, leading some authors to firmly question the transition potential of these initiatives [14]. However, others [15-19] show that the institutional space for these initiatives results not only from local political and public attention to climate change and energy transition but are also conditioned by factors at the macro- and meso-levels.

With regard to the theoretical concepts used, the present contributions all have in common that actors and institutions play a prominent role in explaining the role of cities in energy transition and climate changeoriented initiatives. When developing their analytical frameworks, the authors of the contributions turn to institutionally oriented theories as they have been developed within such disciplines as economy, sociology, planning and law. Within these frameworks, there is a joint focus on analysing the actors involved in transition processes and their incentive structures, informed by actor positions, the resources actors have and the layered institutions that coordinate, guide, influence and sometimes constrain actor behaviour. Furthermore, some of the authors [14, 16, 19] use a co-evolutionary perspective, emphasising-all in their own and sometimes implicit way-the relationship between technological and institutional developments. The focus on policy subsystems reveals how cities-as socio-technical configurations-are made up of subsystems, policy fields or action fields with different actors, interests, ambitions, institutions, discourses and different technological opportunities. Uncoordinated action or competition between different subsystems may be counterproductive (c.f. [18, 19]) and even threaten legitimacy [17]. Alignment within and between subsystems is therefore considered to be a key factor. Again, establishing such alignments calls for situative arrangements, attuned to the specific circumstances and opportunities. Variety in initiatives and the institutional configurations in which they are embedded are therefore considered to be a logical consequence of the unique configuration of cities. The contribution of governance perspectives to study questions of policy design and implementation also reveals that learning from policy initiatives should therefore be especially attuned to the situational mechanisms at work, making the policy (implementation) a success, and not the policy itself (let alone policy 'blueprints' which target multiple cities on the false assumption that situational circumstances are the same). Whereas some policies permit a rather general approach that suits 
multiple cities (particularly with the aim of building capacities), we believe that low carbon policies in urban areas will only be successful if they are adaptive to situational contexts and reflect local actor preferences. Hence, unique situational circumstances in cities call for policy approaches that are tailored to these actual circumstances and are aligned with agendas in local actor configurations.

When viewed in combination, the contributions to this thematic issue offer a rich body of knowledge on the governance of energy transition and climate change mitigation, in addition to the perspectives brought together in the volume by Bulkeley et al. [2]. Although many of the propositions that follow from this volume are supported by evidence from the empirical contributions to this thematic issue, others need more empirical evidence if they are to be nuanced or elaborated. Moreover, this thematic series provides leeway to further a research agenda on governance, politics, policy and institutions regarding low carbon energy transitions in cities. Only using theoretical concepts from urban studies and transition studies (the two central approaches in [2]), and observing that urban low carbon transitions are 'subject to politics and struggle,' will not suffice to further understanding in this way. Therefore, we propose the following research agenda:

- In-depth research into the multiple roles cities can play in low carbon energy transitions, identifying mechanisms of politics, power and policy.

- Systematically mapping practices of design and implementation of urban low carbon energy transition policy.

- Research into the effects (including negative side effects) and legitimacy of policy instruments designed to spur low carbon energy transition in cities.

- Addressing the roles and interrelations between relevant (sectoral) policies in relation to urban low carbon transitions.

- Addressing the practices of multilevel governance in spurring local and regional low carbon energy transitions, studying experiences from cities and city regions. This should not be restricted to best practices only, but study a fairly diverse set of successful and less successful cases in cities and city regions.

- Addressing institutional conditions in multistakeholder configurations, looking into positions, ownership, institutional rules and policies.

- Further understanding of strategic action fields and lines of conflict between (coalitions or networks of) actors having different policy beliefs and pursuing different (non-negotiable) interests.
- Identifying workable governance frameworks and policies supporting community-led energy initiatives.

\section{Competing interests}

The authors declare that they have no competing interests.

\section{Author details}

'Department of Governance and Technology for Sustainability (CSTM),

Faculty of Behaviour, Management and Social Sciences (BMS), University of Twente, P.O. Box 217, Enschede 7500 AE, The Netherlands. ${ }^{2}$ Chair of Urban Development Management, Faculty of Architecture and the Built Environment, Delft University of Technology, P.O. Box 5043, Delft 2600 GA, The Netherlands.

Received: 11 May 2015 Accepted: 29 May 2015

Published online: 26 June 2015

\section{References}

1. Hoppe T, van Bueren E, Sanders M (2013) Naar een bestuurswetenschappelijke onderzoeksagenda voor klimaatmitigatie in Nederland en Vlaanderen. Bestuurswetenschappen 67(2):88-99

2. Bulkeley H, Castan-Broto V, Hodson M, Marvin S (eds) (2013) Cities and low carbon transitions. Routledge, New York, London

3. Bulkeley H, Castan Broto V, Maassen A (2013) Governing urban low carbon transitions. In: Bulkeley H, Castan-Broto V, Hodson M, Marvin S (eds) Cities and low carbon transitions. Routledge, New York, London, pp 29-41

4. Aylett A (2013) Municipal bureaucracies and integrated urban transitions to a low carbon future. In: Bulkeley H, Castan-Broto V, Hodson M, Marvin S (eds) Cities and low carbon transitions. Routledge, New York, London, pp 142-158

5. Späth P, Rohracher H (2013) The 'eco-cities' Freiburg and Graz: the social dynamics of pioneering urban energy and climate governance. In: Bulkeley $\mathrm{H}$ Castan-Broto V, Hodson M, Marvin S (eds) Cities and low carbon transitions. Routledge, New York, London, pp 88-106

6. Geels F (2013) The role of cities in technological transitions: analytical clarifications and historical examples. In: Bulkeley H, Castan-Broto V, Hodson M, Marvin S (eds) Cities and low carbon transitions. Routledge, New York, London, pp 13-28

7. Smith A (2013) Community-led urban transitions and resilience: performing Transition Towns in a city. In: Bulkeley H, Castan-Broto V, Hodson M, Marvin S (eds) Cities and low carbon transitions. Routledge, New York, London, pp 159-177

8. Hopkins R, Lipman P (2009) Who we are and what we do. Transition Network, Totnes

9. Macnaghten P, Urry J (1998) Contested natures, Volume 54. Sage, Thousand Oaks

10. Geels $F$ (2002) Technological transitions as evolutionary reconfiguration processes: a multi-level perspective and a case-study. Res Policy 31:1257-1274

11. Hoppe $T$, Bressers $H$, Lulofs K (2010) Energy conservation in Dutch housing renovation projects. In: Martens $P$, Chiang $C T$ (eds) The social and behavioural aspects of climate change. Greenleaf, Sheffield, pp 68-95

12. Wissner M (2011) The Smart Grid—a saucerful of secrets? Appl Energy 88(7):2509-2518

13. Murphy L, Meijer F, Visscher H (2012) A qualitative evaluation of policy instruments used to improve energy performance of existing private dwellings in the Netherlands. Energy Policy 45:459-468

14. Arentsen M, Bellekom S (2014) Power to the people: local energy initiatives as seedbeds of innovation? Energy Sustain Soc 4:2

15. Oteman M, Wiering M, Helderman J (2014) The institutional space of community initiatives for renewable energy: a comparative case study of the Netherlands, Germany and Denmark. Energy Sustain Soc 4:11

16. Fuchs G, Hinderer N (2014) Situative governance and energy transitions in a spatial context: case studies from Germany. Energy Sustain Soc 4:16

17. Sanders M, Heldeweg M, Straatman E, Wempe J (2014) Energy policy by beauty contests: the legitimacy of interactive sustainability policies at regional levels of the regulatory state. Energy Sustain Soc 4:4

18. Hoppe T, van den Berg M, Coenen F (2014) Reflections on the uptake of climate change policies by local governments: facing the challenges of mitigation and adaptation. Energy Sustain Soc 4:8 
19. Viétor B, Hoppe T, Clancy J (2015) Decentralised combined heat and power in the German Ruhr Valley; assessment of factors blocking uptake and integration. Energy Sustain Soc 5:5

20. Stauskis $G$ (2014) Development of methods and practices of virtual reality as a tool for participatory urban planning: a case study of Vilnius City as an example for improving environmental, social and energy sustainability. Energy Sustain Soc 4:7

Submit your manuscript to a SpringerOpen ${ }^{\circ}$ journal and benefit from:

- Convenient online submission

- Rigorous peer review

- Immediate publication on acceptance

- Open access: articles freely available online

- High visibility within the field

- Retaining the copyright to your article

Submit your next manuscript at $\boldsymbol{\nabla}$ springeropen.com 